\title{
Полицентричность парадигмы урбоэкологического пространственного развития
} Э.В.Сарнацкий, член-корреспондент РАACH, заслуженный строитель РСФСР

\section{Polycentricity of the Paradigm of Urban Ecological Development}

E.V.Sarnatsky, corresponding member of the RAACS, honored builder of the RSFSR

Мироздание имеет в своей основе три основополагающие фактора: материя, энергия и информация. Будущее будет более электрическим, цифровым и экологичным. Мировой и отечественный опыт говорит о том, что градостроительная практика, опирающаяся на научные исследования и технические новации, есть основа сохранения и развития благоприятной среды жизнедеятельности человека и общества в органичном единении с природой. Отсюда родился термин «урбоэкология», введённый в практику градостроительства академиком РААСН Виктором Владимировичем Владимировым.

Градостроитель является системным интегратором когнитивного подхода к социально-экономическому обустройству территорий

Ожидаемая четвёртая промышленная революция (золотой век цифровизации) несёт с собой революционные изменения в отношениях на производстве и в обществе. Одним из главных результатов четвёртой промышленной революции должно стать появление устройств, наделённых разумом и правом принимать решения, и мы, люди, должны будем с ними сосуществовать. Цифровизация производства или экономики в целом - это предтеча четвёртой промышленной революции, и она должна привести к созданию так называемой «Индустрии 4.0».

Наступление «Индустрии 4.0» будет определять, какое место в производстве ценностей будет занимать человек,

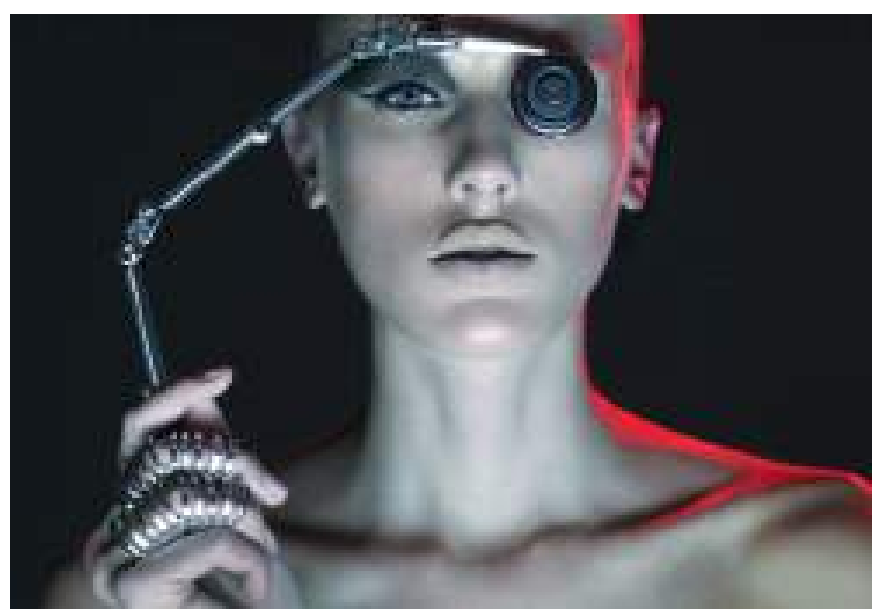

Рис. 1. Каково оно, наше будущее? а какое - созданные человеком устройства. Каждая революция радикально меняет отношения между участниками системы, а также вбирает в себя соответствующие её целям (и даже предшествующие ей) реформы и эволюционные изменения в технологиях и даже в структуре общества.

Технологий много, но они ничего кардинально во всей системе не меняют, а позволяют делать всё то же самое, но чуть быстрее, чуть лучше, чуть качественнее. И лишь единичные технологии можно отнести к революционным - это использование киберфизических устройств, искусственный интеллект и, возможно, предписывающая аналитика.

Материальный мир (данный нам в ощущении?) включает в себя земные показатели - литосферу, аэросферу и гидросферу со всеми исторически принятыми коррекциями, сотворёнными человеком в их позитивном и негативном аспектах.

По оценкам учёных (весьма предварительным), масса техносферы, созданной человеком, сегодня превышает 30 трлн т! Вся органика, которую успела сотворить природа за 4,5 млрд лет существования Земли, вся биомасса, включая и самого Homo sapiens, весит около 2,5 трлн т. При этом суммарная масса всех человеческих тел на Земле составляет всего около ста миллионов тонн.

Почти 95\% из этих общих 30 трлн т приходится всего на пять компонентов: города (36,9\%), сельское жилье $(20,9 \%)$, выгоны (16,7\%), пахотные земли (12,5\%), площади траления морского дна (7,5\%). Для сравнения: замыкают список железные дороги - их вклад в массу глобальной техносферы оценивается в $2 \times 1010$ т (0,1\%).

Видовое разнообразие техносферы уже на три порядка (в тысячу раз) превышает число ныне живущих видов биологических организмов (8,7 млн).

Наш мир - государства и нации, города и мобильность людей в межконтинентальном, меж- и внутристрановом отношении, динамика расселения - прежде всего интересует градостроителей с главным вопросом: каково оно, это наше будущее? То, что наше будущее образуется из нашего «сегодня и вчера», не вызывает отторжения. 0 будущем у нас есть многое в воображаемых картинках при одновременном видении и понимании угроз и вызовов.

Оценка ситуации в мире основывается на анализе состояния и перспектив развития мировой экономики. По аналитическому обзору Всемирного экономического форума (ВЭФ), экономика выбыла из топ-5 рисков ещё в 2016 году (в 2015 году указывалось на проблемы безработицы). Отступили и геополитические угрозы. Опрошенные ВЭФ эксперты и представители бизнеса считают 
наиболее вероятными рисками экологические и технологические. В сентябре 2017 года было зафиксировано максимальное число ураганов, лесных пожаров; 2017 год стал и одним из самых жарких в истории наблюдений. Из-за экологических катастроф в 2017 году около 24 млн человек покинули свои дома.

За некоей радужной картиной (в 2018 году прогнозируется рост глобальной экономики на 3,1\% после 3\% в 2017-м, за счёт чего она приблизится к своему потенциалу или достигнет его после кризиса 2008 года) могут скрываться многочисленные поводы для беспокойства, говорится в докладе ВЭФа: это было наиболее слабое из известных восстановление экономики после рецессии. Рост производительности остаётся на удивление вялым, рост инвестиций - подавленным.

По рейтингу, составленному одним из известных американских еженедельных журналов «US News \& World Report» в январе 2018 года при сотрудничестве с консалтинговой компанией «BAV Consulting» и Университетом штата Пенсильвания, Россия поднялась на одну позицию и заняла 26-е место в рейтинге лучших стран мира. Рейтинг основывается на результатах социологического опроса, проведённого среди примерно 21 тыс. человек со всего мира, в число которых входили как представители бизнес-элиты, так и обычные граждане. Страны оценивались по девяти критериям: развитие туристической отрасли, инноваций, социальной сферы, культуры, темпам роста экономики, открытость для бизнеса, общий уровень жизни населения, а также сила и влияние на мировой арене, историческое наследие. Первое место в рейтинге, в который попали 80 стран, занимает Швейцария. По критерию силы и влияния в мире РФ заняла второе место, уступив лишь США, а третье место в этой строке досталось КНР.

По темпам роста ВВП Россия «с одной из крупнейших экономик в мире» заняла восьмую строчку. После Соединённых Штатов «Россия и Китай воспринимаются как наиболее могущественные страны и входят в четвёрку государств с наиболее крупным военным бюджетом». При этом издание указывает, что в данной части рейтинга «разрыв между США и Россией сужается».

Ситуационные особенности развития экономики России (в условиях санкционного давления и недореформированности) приведены в основных выводах и идеях Гайдаровского форума-2018: низкий государственный долг, стабильная низкая инфляция, борьба с немонетарными факторами инфляции, эксклюзивные налоговые преференции для инвесторов, рост собираемости налогов и борьбы за эффективность госуправления. Общий прогноз - примерно 2\% роста в 2018 году.

Динамика инвестиционного состояния приведена ниже.

Неопределённость экономической ситуации стала самым главным препятствием для работы в России как добывающих, так и обрабатывающих предприятий. Она для бизнеса намного страшнее, чем высокие налоги, низкий спрос, изношенность оборудования или недостаток квалифицированных кадров.

Разочаровывающим обстоятельством явился слабый рост промышленности в 2017 году: по данным Росстата в итоге годовой рост производства замедлился до 1\% - с 1,3\% в 2016 году, что в два раза ниже прогноза Минэкономразвития (2\%) и ниже консенсус-прогноза аналитиков Reuters (1,2\%). При этом заметно выросла по итогам года лишь добыча полезных ископаемых - на 2\%. Обрабатывающие производства и энергетика увеличили выпуск незначительно, а водоснабжение и вовсе сократилось. Негативно сказалось продление срока действия соглашения об ограничении добычи нефти ОПЕК со странами, не входящими в картель, нефтедобыча сократилась на 2,2\%, Обработка упала из-за неожиданного сокращения металлургии, которая, по консенсус-прогнозу, должна была сократиться незначительно. Возможны и ошибки статистики.

При всём при этом предприниматели, не соглашаясь с чиновниками и аналитиками, оценивают ситуацию оптимистично: индекс промышленного оптимизма, по итогам опросов Института Гайдара, в ноябре вырос до многолетнего максимума, хотя инвестиционные планы промышленности ушли в минус. В декабре вырос индекс деловой активности в обрабатывающих отраслях - до максимума с августа 2017 года, не ухудшились (по опросам Центра конъюнктурных исследований Высшей школы экономики) и оценки промышленников. Оптимизм производителей может быть связан с тем, что они оценивают ситуацию относительно нормального в их представлении уровня.

По данным Международной организации труда (МОТ), число безработных в мире по итогам прошлого года достигло рекордных 192,7 млн человек, увеличившись за год на 2,6 млн человек. Уровень мировой безработицы составил 5,6\%. По прогнозу МОТ в 2018 году число безработных в мире будет

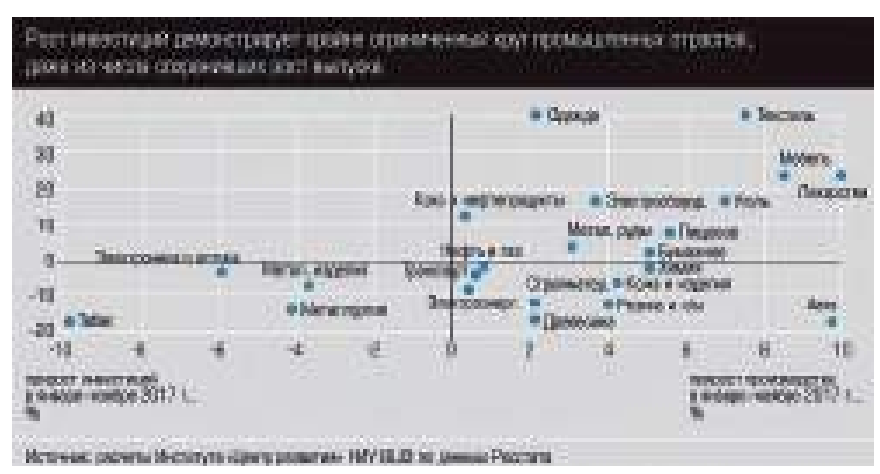

Pис. 2. Инвестиции в экономику

\section{Индустрия ушла в рецессию}

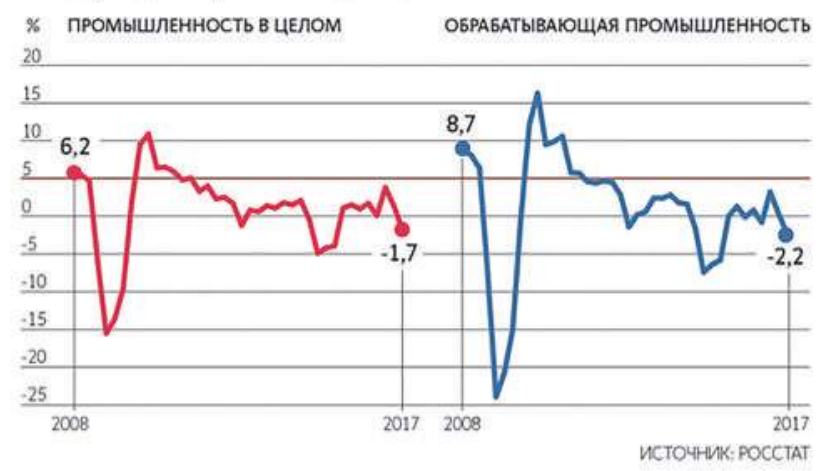

Рис. 3. Индустрия в рецессии 
оставаться практически неизменным, а уровень безработицы стабилизируется после роста в 2016 году. В документе подчёркивается, что дефицит достойного труда остаётся широко распространённым, глобальная экономика всё ещё не создаёт достаточного количества рабочих мест.

Прогноз МОТ в отношении России - уровень безработицы в стране в 2018 году по сравнению с 2017-м уменьшится с 5,2\% (3,9 млн человек) до 5\% (3,8 млн человек); в 2019 году этот показатель будет на уровне 4,9\% (3,6 млн человек).

Энергия не может рассматриваться как самоцель, как некое самоценное благо; в дополнение к природным факторам наличия и проявления энергии человек использует свои возможности для создания (преобразования) различных видов энергии для своих нужд как универсального средства для обеспечения человечества: приемлемых параметров искусственно созданной среды обитания, высокой производительности труда при создании и движении товаров и услуг, возможной мобильности и коммуникаций, наконец - для познания мира. Количеством, качеством и разнообразием благ, получаемых с помощью энергии, определяется уровень развития общества. Академик М. Стырикович дал точное и полновесное определение: энергетика = физика + экономика.

В долгосрочной перспективе, в соответствии с Генеральной схемой размещения объектов электроэнергетики, утверждённой распоряжением правительства РФ от 09 июня 2017 года, объём подлежащей выводу из эксплуатации мощности по достижению паркового ресурса до 2025 года (включительно) в ЕЭС России может составить 32,9 ГВт. Ещё порядка 90 ГВт

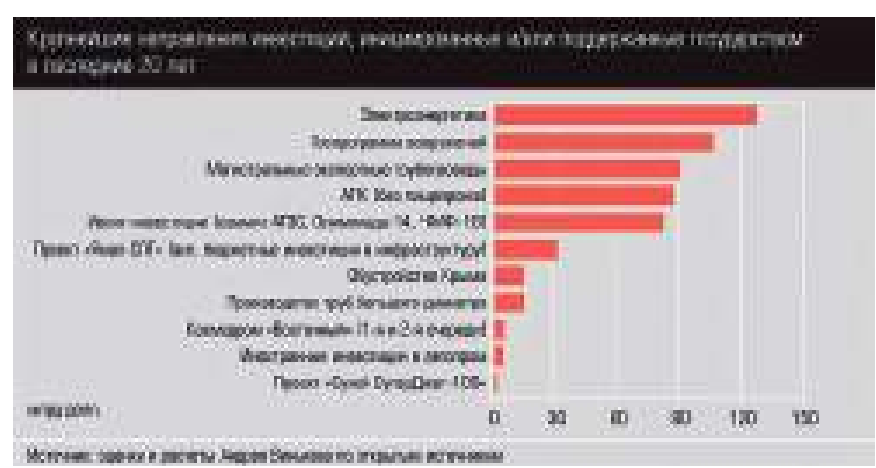

Рис. 4. Направленность инвестиций

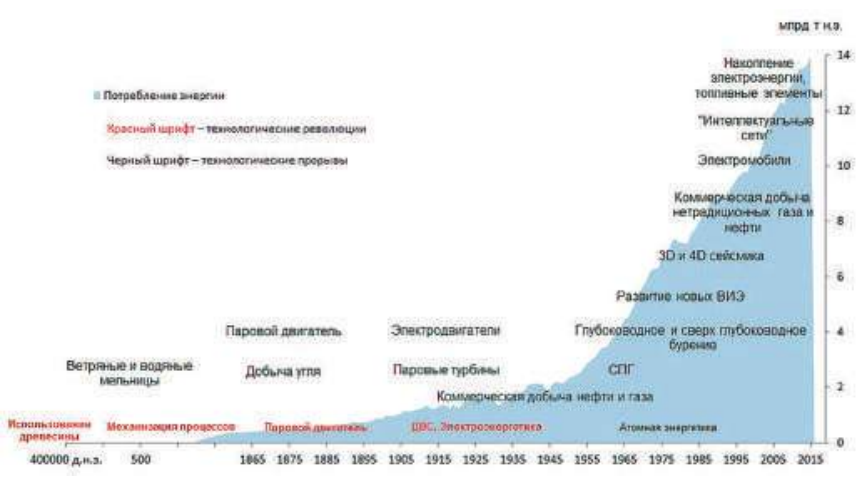

Рис. 5. Рост потребления энергии человечеством (млрд тонн нефтяного эквивалента) потребуют модернизации в связи с исчерпанием паркового pecypca.

Программа модернизации энергомощностей придёт на смену программе строительства новых электростанций. Модернизация тепловых электростанций займёт десять лет: к 2030 году будет обновлено 16\% мощностей - 40 ГВт. На это потребуется 1,5 трлн руб. В программу, помимо станций, расположенных на европейской части России, Урала и Сибири, может быть включён и Дальний Восток.

При этом объёмы вводов новой генерации, подтверждённые инвестиционными планами и обязательствами по поставке мощности на рынок, за вычетом негарантированной мощности ВИЭ, составляют 17 ГВт.

За десятилетие в строительство новых энергоблоков мощностью 27,7 ГВт было инвестировано более 1,3 трлн руб.

По сообщению Минэнерго, к 2025 году планируется увеличение максимума потребления мощности по ЕЭС России на 16,8 ГВт (до 167,9 ГВт), накопленные к настоящему времени избытки мощности могут быть исчерпаны, и ввод новых генерирующих объектов потребуется, уже начиная с 2025 года.

С2007 года началось заключение договоров о предоставлении мощности (ДПМ), гарантировавшей инвесторам возврат вложенных средств в течение пятнадцати лет с базовой доходностью 14\%. Фактически затраты на строительство новых станций были переложены на крупных потребителей. Все, кто закупает электроэнергию на оптовом рынке, были обязаны заключать договоры с энергокомпаниями и оплачивать мощность новых объектов.

Принцип ДПМ заложен и в новую программу модернизации. В докладе, посвящённом вызовам и перспективам технологического развития российской электроэнергетики и формированию предложений по повышениюеё конкурентоспособности, Центр стратегических разработок (ЦСР) при участии экспертов рабочей группы «Энерджинет» НТИ» подготовил ряд предложений.

«Цифровой переход в электроэнергетике позволяет не только повысить эффективность традиционной энергетической системы, но и открывает новые возможности для вовлечения в энергообмен распределённой генерации (в том числе на основе возобновляемых источников энергии), систем накопления энергии, устройств и комплексов с регулируемым потреблением - для организации разнообразных энергетических сервисов. Основные изменения затронут сектор электроэнергетики, находящийся в близости к потребителям и базирующийся на инфраструктуре распределительных сетей 110 кВ и ниже. А структурные и технологические особенности построения энергосистем будут напоминать Интернет. Поэтому новый подход часто называют «Интернет энергии» («Internet of Energy»).

Информация рассматривается как обмен сведениями между людьми (сюда можно добавить автоматы), обмен сигналами в животном и растительном мире, генетическую передачу признаков от клетки к клетке, между организмами... Информатизация - столь же важный ресурс, как вещество и энергия. По своему историческому значению информатизация - новый этап в развитии, сопоставимый с индустриализаци- 
ей; экономическая мощь государства и качество жизни людей сегодня и особенно завтра напрямую связывается с информатизацией. Принято понимать цифровизацию (дигитализацию) как использование возможностей онлайн- и инновационных цифровых технологий всеми участниками экономической системы - от отдельных людей до крупных компаний.

В условиях глобализации формирующееся информационное общество - это новая форма социальной организации, закономерный результат развития и распространения информационной технологии, что вызывает растущую интеллектуализацию производств, городского хозяйства и общества в целом. Предпосылка создания информационного общества (точнее - развития общества в этом направлении) - это процессы создания и развития информационных технологий, что влечёт за собой коренные изменения в сфере труда, в производстве и экономике, в городском хозяйстве, в социальной сфере, в образовании.

Понятие управления как элемента информатизационного процесса напрямую применимо к функционированию городской (застроенной и застраиваемой) среды, прежде всего - к его инженерной и транспортной инфраструктуре. Ресурсопотребляющие, генерирующие и распределительные системы инженерного обеспечения городов и других поселений становятся одним из важнейших факторов градоразвития. Макрофакторные показатели инженерного обеспечения должны закладываться в генеральные градостроительные решения и на этой основе надо находить детализирующие разрешение в программах комплексного развития инженерных систем

В настоящее время мир вступает в эпоху цифровой экономики, которая кардинально изменяет ситуацию:

- основным ресурсом становится информация, а этот источник от использования не иссякает;

- торговые площади в Интернете не ограничены;

- компании не нужно быть большой, чтоб успешно конкурировать;

- масштаб операционной деятельности ограничен только размерами Интернета;

- человек становится «просьюмером» (по Тоффлеру - потребителем и производителем в одном лице).

В условиях глобализации возникают коллизии, которые должны восприниматься как абсолют (при этом иные мнения просто не принимаются даже при их обоснованности). Так, на сегодня (и, быть может, на завтра) возник тезис «безуглеродного мира» (термин сам по себе является нонсенсом - вероятно, здесь следует понимать малоуглеродные выбросы при генерации и потреблении энергии?).

0беспечение социально-ориентированной политики в городах и других поселениях, создание и сохранение гуманистической и экологически благоприятной среды обитания и трудовой деятельности людей, того, что принято называть качеством жизни, - всё это требует создания и совершенствования правовых и нормативных актов, оценки и понимания перспектив развития ресурсов города - того, что он производит, и того, что он потребляет, его роли и значения в регионе и стране, обеспечения безопасности и надёжного развития урбанизированных территорий.

Ресурсы, которые необходимы для жизнеобеспечения города (поселения) соединены в устройстве его инженерных инфраструктур: энергетика (топливо или иные источники энергии, электрическая и тепловая энергия (в том числе холодоснабжение), водоснабжение и водоотведение, технические экологодостаточные средства и способы утилизации отходов производства и потребления, средства транспортной коммуникации, средства связи и телекоммуникации. Их поддержание и развитие укладываются в инфраструктурные особенности поселений и территорий. Вопросы развития социальных инфраструктур требуют отдельного рассмотрения, хотя в большинстве случаев сосуществуют с технологическими инфраструктурами.

\section{Sapienti sat (разумному достаточно)}

Полвека разномастные эксперты убеждают нас, что человек губит планету своей несдержанной хозяйственной деятельностью. Так, по данным РИА «Новости»(январь 2018 года), учёные США и Великобритании подготовили официальное сообщение для американской Национальной академии наук, в котором рассказали, когда жизнь на Земле станет непригодной для человечества, указали на опасность изменения климата, которая представляется неизбежной в связи с ростом потребления энергии даже при сокращении выброса парниковых газов. Потребление энергии непрерывно растёт и сегодня превысило 13 млрд т н.э./год, или в среднем $\approx 2$ т н.э./чел./год или $\approx 3$ кВт/чел. По прогнозам исследователей, температура на Земле станет непригодной для жизни уже к 2200-2400 годам. При этом, на повышение температуры не повлияет вероятное снижение роста населения планеты к 2100 году.

Можно удивляться тому, насколько близко повторяют друг друга апокалиптические предсказания учёных (и псевдотаковых) в 1970-е и в начале 2000-х - слово в слово: парниковый эффект, разрушение озонового слоя, ядовитый углекислый газ, разрушительная роль углеводородов, положение с отходами производства и потребления. Никого не смущает, что страшные пророчества эти не сбываются, а те же самые учёные просто корректируют графики, смещая гибельную кривую ещё на десяток лет, получая многомиллионные гранты на исследование темы с заданным результатом? «Зелёный» заговор настолько

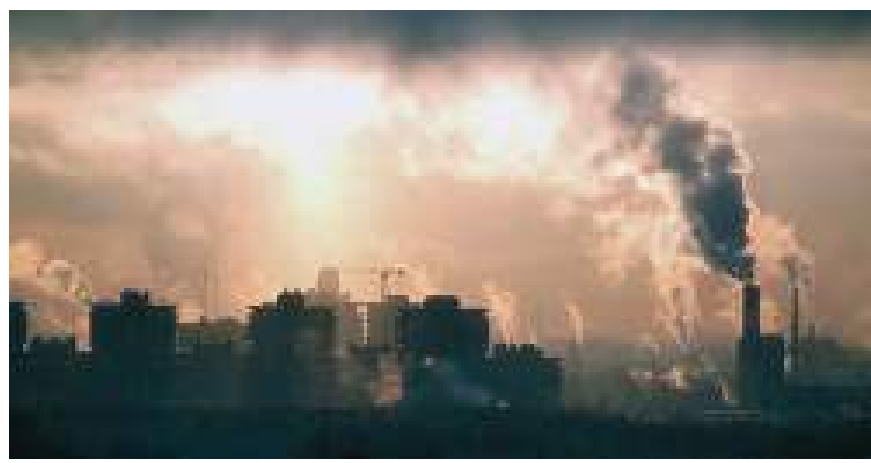

Pис. 6. Так видится городской ландшафт 
доминирует в мировом социуме, что даже владельцы нефтяных и газовых компаний фактически извиняются за свою работу.

Полвека назад «зелёные» активисты и экологи считались интеллектуальными бунтарями против системы. Сегодня же смелостью должен обладать исследователь, выступающий против насаждения так называемых «безвредных технологий будущего».

В дополнение к этому в сторону Земли несутся крупные астероиды, и чрезвычайные земные природные события вызывают тревогу и опасения.

Актуализация задач, стоящих перед академической наукой и согласованных президентом РАН с руководством страны, содержит в себе прогнозирование научно-технологических и социально-экономических процессов в стране, формирование заказа на фундаментальные и прикладные исследования и научную дипломатию (установление и поддержание международных научных контактов). Соответственно этому развитие фундаментальных и поисковых исследований в области градостроительства (урбоэкологической направленности в первую очередь) становится главной задачей РАACH. Можно предположить, что здесь требуется решение ряда организационных, государственного уровня задач. Так, назрела необходимость раздела Министерства образования и науки на Минобразования (важнейшие задачи образовательного характера) и структуру, организующую регулирование на соединении запросов общества и государства и регулирования взаимодействия академической, отраслевой и университетской науки на основе эффективного в советское время Государственного комитета по науке и технике СССР. Автору данного исследования доводилось участвовать в ряде образованных ГКНТ советов по актуальным проблемам с включением в их состав представителей «научного трио»академической, отраслевой и вузовской науки. В этих советах комплексно решались все важнейшие вопросы - от фундаментальных исследований до практической реализации. Здесь же практически и достаточно эффективно решались задачи научной дипломатии. На основе деятельности таких советов формировался государственный заказ на науку. Сегодня такой процесс называют инновационным.

В такой орган следует передать решение многих организационных вопросов взаимодействия «научного трио», передать сюда Российский фонд фундаментальных исследований и другие организации финансирования науки, в частности, ФАНО с более определёнными для него функциями без административной фанаберии.

В области градостроительной с учётом функциональных задач Минстроя следует реанимировать деятельность некогда эффективной Академии коммунального хозяйства. Должен быть разработан комплекс строительных норм и правил; взамен тысяч нормативных и административных уложений (имя им «легион», и они меняются быстрее чернил в принтерах, а исполнение затруднено), в области экологической природозащитной чересполосицы необходимо разработать Экологический кодекс.
Государство и общество должны иметь строгую и ясную систему государственного заказа на науку.

\section{Лuтература}

1. Владимиров, В.В. Управление градостроительством и территориальным развитием / В.В. Владимиров; Труды PAACH. - М., 2000. - 89 c.

2. Путин, В.В. Прямая речь / В.В. Путин. В 3-х т. - М.: Звонница-МГ, 2016.

3. Сарнацкий, Э.В. «Градостроитель как системный интегратор когнитивного подхода к социально-экономическому обустройству территорий» / Э.В. Сарнацкий // Вопросы профессионализма в территориальном планировании: сборник материалов «Владимировских чтений». - Москва - Ростовна- Дону, 2012.

4. Медоуз, Д. Пределы роста. 30 лет спустя / Д. Медоуз, Й. Рандерс, Д. Медоуз. Пределы роста; Пер. с англ. - М.: ИКЦ «Академкнига», 2007. - 342 с.: ил.

5. Сарнацкий, Э.В. Выбранные места из дискуссий о градостроительной тематике / Э.В. Сарнацкий // Градостроительство. - 2011. - № 2.

6. Материалы научно-практической конференции «Стратегия планирования устойчивого развития крупных городов на примере города Москвы», посвящённой актуальным проблемам градостроительного развития города Москвы; Москва, июнь 2007.

7. Любовный, В.Я. Города России: альтернативы развития и управления / В.Я. Любовный. - М.: Экон-информ, 2013.

8. Вильнер, М.Я. Основы территориального планирования в Российской Федерации / М.Я. Вильнер. - М.: НП «СРОСЭКСПОРТ», 2013.

9. Гутников, В.А. Государственная экспертиза инвестиционных проектов / В.А. Гутников. - М.: РУДН, 2013.

10. Флорида, Р. Креативный класс: люди, которые меняют будущее / Р. Флорида. - М.: Классика-XXI, 2011. - 430 с.

11. Гурова, T. Братство в территориальных границах / Т. Гурова. - М.: Группа Эксперт, 2013.

12. Сарнацкий, Э.В. 0 демографических и миграционных вероятиях как важных факторах градостроительного развития в условиях глобализации / Э.В. Сарнацкий; РАAСН // Фундаментальные исследования РААСН по научному обеспечению развития архитектуры, градостроительства и строительной отрасли Российской Федерации в 2014 году: Сб. науч. тр. РАAСН. - Москва-Курск, 2015.

13. Piketty, T. Capital in Twenty-First Century / T. Piketty. Cambridge, Massachusetts, London England, 2014.

14. Сарнацкий, Э.В. «Камо грядеши» для Зеленограда 2022 (Город, в котором хотелось бы жить) / Э.В. Сарнацкий // Вестник ВолгГАСУ. Серия: Строительство и архитектура. Вып. 31 (50). Ч. 1. «Города России. Проблемы проектирования и реализации». - Волгоград, 2013. - С. 175-179.

15. Климатическая доктрина Российской Федерации [Электронный ресурс] // Информационно-правовой портал «Га- 
рант.ру». - Режим доступа: http://www.garant.ru/products/ ipo/prime/doc/2070243/ (дата обращения 16.02.2018).

16. Примаков, Е.М. Россия. Надежды и тревоги / Е.М. Примаков. - М.: Центрполиграф, 2015.

17. Сарнацкий, Э.В. Инфраструктурные особенности в градостроительном развитии / Э.В. Сарнацкий // Градостроительство. - 2015. - № 5 (39).

18. Веллер, М. Накануне неизвестно чего / М. Веллер. М.: АCT, 2016.

19. Сарнацкий, Э.В. Энигма урбанистической футурологии / Э.В. Сарнацкий // Градостроительство. - 2017. - № 3 (49).

20. Сарнацкий, Э.В. 0 полицентричности энергетической парадигмы в градостроительном развитии / Э.В. Сарнацкий, В.Я. Пейсахович // Фундаментальные, поисковые и прикладные исследования РААСН по научному обеспечению развития архитектуры, градостроительства и строительной отрасли Российской Федерации в 2016 году: Сб. науч. тр. РААСН. Т. 1. - M.: ACB, 2017. - C. 448-457.

\section{Literatura}

1. Vladimirov V.V. Upravlenie gradostroitel'stvom i territorial'nym razvitiem / V.V. Vladimirov; Trudy RAASN. - M., 2000. - 89 s.

2. Putin V.V. Pryamaya rech' / V.V. Putin. V 3-h t. - M.: Zvonnitsa-MG, 2016.

3. Sarnatskij E.V. «Gradostroitel' kak sistemnyj integrator kognitivnogo podhoda k sotsial'no-ekonomicheskomu obustrojstvu territorij»/ E.V. Sarnatskij // Voprosy professionalizma $v$ territorial'nom planirovanii: sbornik materialov «Vladimirovskih chtenij». - Moskva - Rostov-naDonu, 2012.

4. Medouz D. Predely rosta. 30 let spustya / D. Medouz, J. Randers, D. Medouz. Predely rosta; Per. s angl. - M.: IKTS «Akademkniga», 2007. - 342 s.: il.

5. Sarnatskij E.V. Vybrannye mesta iz diskussij 0 gradostroitel'noj tematike / E.V. Sarnatskij // Gradostroitel'stvo. - 2011. - № 2.

6. Materialy nauchno-prakticheskoj konferentsii «Strategiya planirovaniya ustojchivogo razvitiya krupnyh gorodov na primere goroda Moskvy», posvyashhennoj aktual'nym problemam gradostroitel'nogo razvitiya goroda Moskvy; Moskva, iyun' 2007.
7. Lyubovnyj V.Ya. Goroda Rossii: al'ternativy razvitiya $i$ upravleniya / V.Ya. Lyubovnyj. - M.: Ekon-inform, 2013.

8. Vil'ner M.Ya. Osnovy territorial'nogo planirovaniya $v$ Rossijskoj Federatsii / M.Ya. Vil'ner. - M.: NP «SROSEKSPORT», 2013.

9. Gutnikov V.A. Gosudarstvennaya ekspertiza investitsionnyh proektov / V.A. Gutnikov. - M.: RUDN, 2013.

10. Florida R. Kreativnyj klass: lyudi, kotorye menyayut budushhee / R. Florida. - M.: Klassika-XXI, 2011. - 430 s.

11. Gurova T. Bratstvo v territorial'nyh granitsah / T. Gurova. - M.: Gruppa Ekspert, 2013.

12. Sarnatskij E.V. 0 demograficheskih i migratsionnyh veroyatiyah kak vazhnyh faktorah gradostroitel'nogo razvitiya v usloviyah globalizatsii / E.V. Sarnatskij; RAASN // Fundamental'nye issledovaniya RAASN po nauchnomu obespecheniyu razvitiya arhitektury, gradostroitel'stva i stroitel'noj otrasli Rossijskoj Federatsii v 2014 godu: Sb. nauch. tr. RAASN. - Moskva-Kursk, 2015.

14. Sarnatskij E.V. «Kamo gryadeshi» dlya Zelenograda - 2022 (Gorod, v kotorom hotelos' by zhit') / E.V. Sarnatskij // Vestnik VolgGASU. Seriya: Stroitel'stvo i arhitektura. Vyp. 31 (50). Ch. 1. «Goroda Rossii. Problemy proektirovaniya i realizatsii». Volgograd, 2013. - S. 175-179.

15. Klimaticheskaya doktrina Rossijskoj Federatsii [Elektronnyj resurs] // Informatsionno-pravovoj portal «Garant. ru». - Rezhim dostupa: http://www.garant.ru/products/ipo/ prime/doc/2070243/ (data obrashheniya 16.02.2018).

16. Primakov E.M. Rossiya. Nadezhdy i trevogi / E.M. Primakov. - M.: Tsentrpoligraf, 2015.

17. Sarnatskij E.V. Infrastrukturnye osobennosti v gradostroitel'nom razvitii / E.V. Sarnatskij // Gradostroitel'stvo. - 2015. - № 5 (39).

18. Veller M. Nakanune neizvestno chego / M. Veller. - M.: AST, 2016.

19. Sarnatskij E.V. Enigma urbanisticheskoj futurologii / E.V. Sarnatskij // Gradostroitel'stvo. - 2017. - № 3 (49).

20. Sarnatskij E.V. 0 politsentrichnosti energeticheskoj paradigmy $\vee$ gradostroitel'nom razvitii / E.V. Sarnatskij, V.Ya. Pejsahovich // Fundamental'nye, poiskovye i prikladnye issledovaniya RAASN po nauchnomu obespecheniyu razvitiya arhitektury, gradostroitel'stva i stroitel'noj otrasli Rossijskoj Federatsii v 2016 godu: Sb. nauch. tr. RAASN. T. 1. - M.: ASV, 2017. - S. 448-457. 